\title{
Proteomic analysis identifies differentially expressed proteins in AML1/ETO acute myeloid leukemia cells treated with DNMT inhibitors azacitidine and decitabine
}

\author{
Francesca Buchi, Elena Spinelli, Erico Masala, Antonella Gozzini, Alessandro Sanna, Alberto Bosi, \\ Germano Ferrari, Valeria Santini*
}

Functional Unit of Hematology, University of Florence, Florence, Italy

\section{A R T I C L E I N F O}

Article history:

Received 5 August 2011

Received in revised form 28 October 2011

Accepted 29 November 2011

Available online 9 January 2012

\section{Keywords:}

AML

Proteomics

Azacitidine

Decitabine

\begin{abstract}
A B S T R A C T
Azacitidine and decitabine are DNA methyltransferase inhibitors used to treat myelodysplastic syndromes and acute myeloid leukemias. To further characterize different mechanisms between these two agents, cellular extracts from leukemic cells untreated or treated with either drug were analyzed using 2D electrophoresis. Numerous differentially expressed proteins were identified with MALDI-TOF/TOFMS. Cyclophilin A, Catalase, Nucleophosmin and PCNA were decreased exclusively by azacitidine, TCP1 and hnRNP A2/B1 by both drugs; alpha-Enolase and Peroxiredoxin-1 by decitabine. Interestingly, the expression of the proinflammatory protein Cyclophilin A, also suggested as marker of cell necrosis, was stimulated by decitabine. Finally, a comprehensive pathway analysis of data highlighted a relationship between the identified proteins and potential effectors.
\end{abstract}

(C) 2011 Elsevier Ltd. All rights reserved.

\section{Introduction}

5'-Azacitidine and 5'-aza-deoxycytidine - decitabine are ring analogs of cytosine and deoxy-cytosine, differing from the natural nucleoside because of nitrogen in lieu of carbon in position 5 of the pyrimidine. The efficacy of azacitidine and decitabine as antineoplastic agents, widely used for treatment of myelodysplastic syndromes (MDS) and acute myeloid leukemia (AML) of the elderly, is attributed to two distinct mechanisms: cytotoxicity and induction of DNA hypomethylation [1,2]. Azacitidine is transformed into the active nucleotide, 5-aza-2'-deoxycytidine-5'-triphosphate, through ATP-dependent phosphorylation by uridine-cytidine kinase and subsequent activity of ribonucleotide reductase. Previous and recent incorporation studies in leukemic cells have shown that the distribution of AZA in nucleic acids is 65:35, RNA:DNA $[3,4]$. Decitabine, quite differently, incorporates primarily into DNA after deoxycytidine kinase mediated phosphorylation. Regional hypomethylation is thought to be the principal and shared responsible for the clinical efficacy of DNA methyltransferase (DNMT) inhibitors. In fact, once incorporated into DNA, by covalently trapping DNMT, both these drugs deplete the treated cells of functionally active DNMT 1, resulting in reversible but profound

\footnotetext{
* Corresponding author at: Functional Unit of Hematology, University of Florence, AOU Careggi, Largo Brambilla 3, 50141 Florence, Italy. Tel.: +39 0557947296; fax: +390557947343.

E-mail address: santini@unifi.it (V.Santini).
}

hypomethylation and re-expression of silenced oncosuppressor genes.

There are few direct comparisons of the two agents in vivo or in vitro, but their difference in metabolism and DNA incorporation suggests possible diverse mechanisms of action and biological effects $[3,5,6]$.

We and others have previously demonstrated that AML1/ETO positive leukemic cells are preferentially sensitive to epigenetic drugs $[7,8]$ and specifically to DNMT inhibitors [9-11]. We utilized a two-dimensional electrophoresis system, followed by MALDI-TOF/MS to analyze the regulation of protein expression in AML1/ETO positive cells, to further define the mechanism of action of azacitidine and decitabine, as well as possible differences in their biological activity in this particularly suitable cellular model.

\section{Materials and methods \\ 2.1. Cells and culture conditions}

Kasumi-1 cells (a human AML1/ETO-positive cell line derived from an acute myeloblastic leukemia) were plated at $3 \times 10^{5} \mathrm{cell} / \mathrm{ml}$ in RPMI 1640 medium supplemented with $10 \%$ Fetal Bovine Serum (FBS) (Gibco), 4 mM glutamine, 50 units $/ \mathrm{ml}$ penicillin and $50 \mu \mathrm{g} / \mathrm{ml}$ streptomycin at $37^{\circ} \mathrm{C}$ in a humidified atmosphere containing $5 \% \mathrm{CO}_{2}$. Cells from human bone marrow aspirates were obtained after informed consent (previously approved by the local Ethical Committee), provided by 2 AML patients with $t(8 ; 21)$, undergoing routine diagnostic and investigational procedures. In all the experiments, mononuclear cells isolated by density gradient centrifugation with Lympholyte (CEDERLANE-Canada), and Kasumi- 1 cells were incubated in the presence or absence of freshly prepared 5-azacitidine (Sigma-Aldrich) $1.0 \mu \mathrm{M}$ and decitabine (Sigma-Aldrich) $0.5 \mu \mathrm{M}$ for $24 \mathrm{~h}$. Equipotent concentrations of drugs were chosen on the basis of their hypomethylating activity as previously published $[3,12]$. 


\subsection{Protein extraction and $2 D$ electrophoresis}

Cells after $24 \mathrm{~h}$ incubation were washed twice in cold PBS plus $100 \mu \mathrm{M}$ sodium orthovanadate and Protease Inhibitor Cocktail (Sigma). About $20 \times 10^{6}$ cells were lysed, and after ultracentrifugation $\left(100,000 \times g, 1 \mathrm{~h}, 4^{\circ} \mathrm{C}\right)$, protein concentration determined by Bradford assay (Roche). Two-dimensional (2D) electrophoresis was performed as previously described [13].

\subsection{Image analysis and 2D gel comparison}

Two-dimensional gel images were acquired by a modified UMAX Utah.1100 Image Scanner (Amersham Biosciences, Uppsala, Sweden), at 1200 dpi of resolution. Gels were analyzed and compared using the software Image Master Platinum Ed. (Version 5.0, Amersham Biosciences, Uppsala, Sweden). Protein abundance was evaluated by comparing the Spot Staining Volume as calculated by Image Master Platinum ed. Gels were run in duplicate for each sample and scatter plot v/v for the matching spot pools were obtained to verify the degree of reproducibility among two replicates of each sample.

\subsection{In gel digestion and mass spectrometry}

Spots to be identified were excised from the gels, de-stained and subjected to tryptic in-gel digestion with Sequencing Grade Modified Trypsin (Promega, WI) at $37^{\circ} \mathrm{C}$ for $2 \mathrm{~h}$. The resulting peptides were treated by Zip-Tip $\mathrm{C}_{18}$ (Millipore), directly eluted by $2 \mu \mathrm{l}$ of Matrix solution ( $5 \mathrm{~g} / \mathrm{l} 2,5$-dihydroxybenzoic acid in $50 \%$ ACN, $0.1 \%$ TFA), on 384 position- 400 ( $\mathrm{m} \varnothing$ Anchor Chip Target (Bruker Daltonics, Bremen, Germany). Mass spectra for Peptide Mass Fingerprinting (PMF) were acquired in reflectron positive ion mode on Ultraflex MALDI-TOF/TOF Mass Spectrometer (matrix assisted laser desorption/ionization time-of-flight, Bruker Daltonics, Bremen, Germany), with an average of 100 laser shots/spectrum. Spectra were externally calibrated using a combination of four standard peptides: angiotensin II (1046.54 Da), substance P(1347.74 Da), bombesin (1619.82 Da) and ACTH18-39 Clip human (2465.20 Da), spotted onto positions adjacent to the samples. Experimental Peptide Mass Fingerprinting in the range of 600-3500 Da was compared with NCBI protein database by the software MASCOT (www.matrixscience.org). Confirmatory fragmentation analyses (MS/MS) were performed when needed.

\subsection{Western blotting}

Kasumi-1 and human primary $t(8 ; 21)$ AML cells were washed in cold PBS plus $100 \mu \mathrm{M}$ sodium orthovanadate and Protease Inhibitors Cocktail (Sigma) and lysed by incubating at $95^{\circ} \mathrm{C}$ in Laemmli buffer $(62.5 \mathrm{mM}$ Tris/ $\mathrm{HCl} \mathrm{pH} 6.8,10 \%$ glycerol, $0.005 \%$ blue bromophenol and $2 \%$ SDS). Protein concentration was determined by BCA assay (Pierce), $30 \mu \mathrm{g}$ aliquot of each sample was separated by SDS-PAGE (9, 12.5 or $15 \%$ polyacrylamide gels) and then transferred onto PVDF membranes (Hybond-ECL; Amersham Biosciences) by electro blotting. Membranes were incubated with primary antibodies (anti-calreticulin, anti-alpha-Enolase, anti-hnRNP A2/B1, anti-HSP60, anti-HSP70, anti-HSP90 $\alpha / \beta$, anti PRX I, anti TCP1 $\beta$, by Santa Cruz Biotechnology; anti-cyclophilin A, anti-GAPDH, anti-PCNA, anti- $\alpha$-tubulin, by Cell Signaling Technology, anti- $\beta$-tubulin by Upstate, $1: 100016-18 \mathrm{~h}$ at $4{ }^{\circ} \mathrm{C}$ in PBS containing $0.1 \%$ Tween 20 and $5 \%$ BSA (T-PBS/5\% BSA). To verify equal loading of sample per lane, membranes were incubated in stripping buffer $(62.5 \mathrm{mM}$ Tris- $\mathrm{HCl} \mathrm{pH} 6.7$, $2 \% \mathrm{SDS}, 100 \mathrm{mM}$ 2-mercaptoethanol; $30 \mathrm{~min}$ at $50^{\circ} \mathrm{C}$ ) and extensively washed with T-PBS; then the same membranes were incubated in a 1:1000 dilution of anti-p38 (Cell Signaling Technology) in T-PBS/\%5 BSA $\left(16-18 \mathrm{~h}\right.$ at $\left.4{ }^{\circ} \mathrm{C}\right)$. Horseradish peroxidase conjugate secondary antibodies anti-rabbit IgG (Sigma) (1:5000 in T-PBS/2\% BSA; 45 min at room temperature) were employed. Immunoblot were washed in TPBS and antibody coated protein bands were visualized by ECL chemiluminescence detection (Amersham Biosciences).

\subsection{Data analysis}

Scanned images were analyzed by Image Master Platinum Ed. Version 5.0 (Amersham Biosciences). In order to analyze reproducibility, gel similarities or experimental variations, Scatter plots analysis was performed by software Image Master Platinum Ed. which calculates the linear dependence between spot values of one gel in comparison to another gel. For each protein we calculated ratio between spot volume in CTRL gel and spot volume in treated gel. After mass spectrometry analysis and identification by software MASCOT (www.matrixscience.org), proteins were classified by ExPASy Proteomic Server (http://expasy.org/) with UniProtKB database (http://www.uniprot.org). Functional categories were performed using David Bioinformatics Resources 6.7 database (http://david.abcc.ncifcrf.gov/) and cut off criteria used were a p-value of less than 0.001 using Benjamini-Hochberg correction.

Protein network analyses - The proteins identified by MS were included in a pathway analysis using the MetaCore ${ }^{\mathrm{TM}}$ network building (tool GeneGo Inc., St. Joseph, MI - http://www.genego.com/training.php). MetaCore ${ }^{\mathrm{TM}}$ is formed by an annotated database of protein interactions and metabolic reactions. Gene names of the all identified proteins and the corresponding mean fold-change values of such proteins were imported into MetaCore ${ }^{\mathrm{TM}}$ and processed using the network analysis algorithm. Like that, some networks were built. Pathways and direct and indirect associations among proteins were also investigated using String databases (Version 8.3, http://string-db.org/)

\section{Results}

\subsection{Proteomic comparison after treatment with DNMT inhibitors}

Protein gels were reproducible, as verified by scatter plot $\mathrm{v} / \mathrm{v}$ among the replicates of each condition of culture (Fig. S1, a and b - Supplementary data). Changes of protein expression after $24 \mathrm{~h}$ azacitidine and decitabine treatment were considered significant when their quantity decreased or increased by at least 1.3 -fold.

\subsection{Treatment with 5-azacitidine}

According to image analysis, 620 spots were constantly detected in control gel and 486 spots in treated cell gel and were quantified, normalized, inter gel matched, yielding 400 pairs of proteins. Sixtyfour protein spots had significant volume differences occurring between untreated control and azacitidine treated, and we excised 51 protein spots from control gel and 13 spots from treated-cell gel. Mass spectrometry analysis by MALDI-TOF allowed us to successfully identify 43 protein spots whose levels changed (Fig. 1A, a and b) corresponding to 30 characteristic proteins, classified in functional categories by David Bioinformatics database. Results were reported in Table 1: Spot number obtained from Image Master correlates to corresponding spots in Fig. 2A.

As shown in Fig. 1B, nine proteins (30\%) identified by MS included molecules functionally classified as Heat Shock Proteins/Chaperons, nine proteins (30\%) were enzymes, most of which metabolic, one protein was involved in stress/redox homeostasis, five $(17 \%)$ were structural proteins and six proteins (20\%) were involved in signal transduction (Table 1 and Supplementary data). The majority of the detected proteins decreased after azacitidine treatment, as showed by the ratio of the volume of spots in treated and untreated cells (Table 1) and, after String analysis, we observed that all proteins were linked by different characteristics, and were involved in several neoplastic diseases (Fig. S2, a - Supplementary data).

Differential expression of PCNA, TCP1, hnRNP A2/B1 and Cyclophilin A was confirmed by western blot (Fig. 1C, a and b). Cyclophilin A, in particular, was identified by more than one spot in 2D maps, because of its different isoforms which could be presents, and its global expression in azacitidine treated cells was lower than that in untreated cells. Regarding biological variation of hnRNP A2/B1, western blot analysis showed an inhibition of expression of ribonucleoprotein B1 and an increase of A2, but global protein expression decreased (ratio of densitometry CTRL/AZA: 1.3, respect to loading control) (Fig. 1C, a and b).

We observed in 2D gels different spots of alpha-Tubulin, beta-Tubulin, alpha-Enolase, ACTB, HSP90, HSP70 and Calreticulin (Table 1 - marked with an asterisk), due to the presence of several isoforms. For this reason, global expression of these proteins was unmodified after azacitidine (Fig. 1C, c). Isoforms of these proteins, well separated by 2D electrophoresis, in 1D western blot clustered in the same band, precluding the validation of difference in expression.

The decrease of Cyclophilin A, PCNA and TCP1 beta was confirmed by western blot with specific antibodies also in primary cultures of 2 AML $t(8 ; 21)$ cases after exposure of leukemic cells to azacitidine (Fig. 1D, a and b).

\subsection{Treatment with decitabine}

After image analysis, 576 spots were detected in control cells and 596 spots in treated cells; two gels were matched and 416 pairs 
Table 1

Differentially expressed proteins identified by mass spectrometry after azacitidine treatment.

\begin{tabular}{|c|c|c|c|c|c|c|c|c|c|}
\hline Spot CTRL & Spot AZA & $\begin{array}{l}\text { Accession } \\
\text { number }^{\mathrm{a}}\end{array}$ & Heat Shock Proteins/Chaperons & $\mathrm{MW}^{\mathrm{b}}$ & $\mathrm{pl}^{\mathrm{c}}$ & $\mathrm{SCORE}^{\mathrm{d}}$ & Vol. C/Vol. A $\mathrm{e}^{\mathrm{e}}$ & $\begin{array}{l}\text { Induced or } \\
\text { overexpressed by AZA }\end{array}$ & $\begin{array}{l}\text { Inhibited or } \\
\text { reduced by AZA }\end{array}$ \\
\hline C98 & A69 & P14625 & Endoplasmin* ${ }^{*}$ & 92,637 & 4.73 & 155 & 1.2 & & $\mathrm{x}$ \\
\hline C96 & A61 & P14625 & Endoplasmin* & 90,351 & 4.73 & 32 & 0.4 & $\mathrm{x}$ & \\
\hline C9 & & P07900 & Heat shock protein $90 \mathrm{kDa}$ alpha, class B member $1^{*}$ & 83,638 & 4.94 & 75 & CTRL & & $\mathrm{x}$ \\
\hline C121 & A82 & P07900 & Heat shock protein $90 \mathrm{kDa}$ alpha, class B member $1^{*}$ & 83,638 & 4.94 & 173 & 2.1 & & $\mathrm{x}$ \\
\hline C139 & A94 & P07900 & Heat shock protein $90 \mathrm{kDa}$ alpha, class B member $1^{*}$ & 83,638 & 4.94 & 69 & 0.5 & $\mathrm{x}$ & \\
\hline C113 & A83 & P07900 & Heat shock protein $90 \mathrm{kDa}$ alpha (cytosolic), class B member $1^{*}$ & 83,638 & 4.94 & 46 & 0.5 & $\mathrm{x}$ & \\
\hline C181 & A125 & P11142 & Heat shock $70 \mathrm{kDa}$ protein $8^{*}$ & 71,138 & 5.37 & 186 & 2.5 & & $\mathrm{x}$ \\
\hline C178 & A123 & P11142 & Heat shock $70 \mathrm{kDa}$ protein $8^{*}$ & 71,138 & 5.37 & 49 & 0.8 & $\mathrm{x}$ & \\
\hline $\mathrm{C} 216$ & A151 & P10809 & Heat shock protein 60 & 61,388 & 5.24 & 219 & 1.0 & & \\
\hline C249 & A184 & P78371 & Chaperonin containing TCP1, subunit 2 (beta) & 57,878 & 6.02 & 153 & 1.8 & & $\mathrm{x}$ \\
\hline C173 & A119 & P38646 & Heat shock $70 \mathrm{kDa}$ protein 9 & 74,089 & 5.97 & 117 & 1.2 & & $\mathrm{x}$ \\
\hline C862 & A528 & P62937 & Cypa (Cyclophilin A)* & 18,154 & 7.82 & 146 & 0.8 & $\mathrm{x}$ & \\
\hline C710 & A524 & P62937 & Cypa (Cyclophilin A)* & 18,154 & 7.82 & 98 & 1.4 & & $\mathrm{x}$ \\
\hline C705 & A523 & P62937 & Cypa (Cyclophilin A)* & 18,154 & 7.82 & 103 & 1.2 & & $\mathrm{x}$ \\
\hline \multirow[t]{2}{*}{ C263 } & A173 & P27797 & Calreticulin* & 48,325 & 4.28 & 75 & 2.2 & & $\mathrm{x}$ \\
\hline & A306 & P27797 & Calreticulin* & 48,325 & 4.28 & 46 & AZA & $\mathrm{x}$ & \\
\hline C235 & & P30101 & Protien-disulfide isomerase A3 & 56,761 & 5.61 & 83 & CTRL & & $\mathrm{x}$ \\
\hline \multicolumn{10}{|l|}{ Enzymes } \\
\hline C295 & A208 & P06733 & Alpha-Enolase* & 47,538 & 6.99 & 61 & 0.4 & $\mathrm{x}$ & \\
\hline C292 & A213 & P06733 & Alpha-Enolase* & 47,538 & 6.99 & 94 & 1.5 & & $\mathrm{x}$ \\
\hline C268 & A199 & P07237 & Prolyl 4-hydroxylase beta-subunit & 57,578 & 4.69 & 211 & 1.4 & & $\mathrm{x}$ \\
\hline $\mathrm{C} 236$ & A163 & P12268 & Inosine monophosphate dehydrogenase 2 & 56,338 & 6.44 & 115 & 1.5 & & $\mathrm{x}$ \\
\hline C470 & A355 & P04406 & Glyceraldehyde-3-phosphate dehydrogenase & 36,244 & 8.58 & 91 & 1.5 & & $\mathrm{x}$ \\
\hline C546 & A415 & P60174 & Chain B, Triosephosphate Isomerase (Tim) & 26,877 & 6.51 & 191 & 1.2 & & $\mathrm{x}$ \\
\hline C538 & A406 & P28066 & Proteasome subunit, alpha type, 5 & 26,621 & 4.74 & 46 & 1.4 & & $\mathrm{x}$ \\
\hline C815 & & P55072 & Valosin-containing protein & 71,660 & 5.14 & 49 & CTRL & & $\mathrm{x}$ \\
\hline C665 & A487 & P15531 & Non-metastatic cells 1, protein (NM23A) isoform a & 19,925 & 5.84 & 64 & 2.7 & & $\mathrm{x}$ \\
\hline C226 & A157 & P04040 & Catalase & 59,947 & 6.95 & 93 & 1.8 & & $\mathrm{x}$ \\
\hline \multicolumn{10}{|c|}{ Cell redox homeostasis } \\
\hline C596 & A446 & P09211 & Glutathione S-transferase P & 23,651 & 5.44 & 86 & 1.4 & & $\mathrm{x}$ \\
\hline \multicolumn{10}{|c|}{ Structural proteins } \\
\hline C253 & A191 & P68363 & Alpha tubulin* & 50,972 & 4.94 & 149 & 1.9 & & $\mathrm{x}$ \\
\hline $\mathrm{C} 260$ & A194 & P68363 & Alpha tubulin* & 50,972 & 4.94 & 106 & 0.5 & $\mathrm{x}$ & \\
\hline C280 & A204 & P68363 & Alpha tubulin* & 50,972 & 4.94 & 60 & 0.9 & & \\
\hline C445 & A334 & P07437 & Beta tubulin* & 48,233 & 4.78 & 182 & 1.6 & & $\mathrm{x}$ \\
\hline C421 & & P07437 & Beta tubulin* & 48,233 & 4.78 & 127 & CTRL & & $\mathrm{x}$ \\
\hline C284 & & P07437 & Beta tubulin* & 48,233 & 4.78 & 70 & CTRL & & $\mathrm{x}$ \\
\hline C365 & A274 & P60709 & ACTB protein (Beta-actin)* & 40,620 & 5.29 & 142 & 1.8 & & $\mathrm{x}$ \\
\hline C330 & A251 & P60709 & ACTB protein $($ Beta-actin)* & 40,620 & 5.29 & 48 & 0.8 & $\mathrm{x}$ & \\
\hline C413 & A314 & P52907 & F-actin capping protein alpha 1 & 33,115 & 5.45 & 118 & 2.7 & & $\mathrm{x}$ \\
\hline C475 & A362 & Q8TCG3 & Tropomysin, TPMsk3 & 28,934 & 4.72 & 74 & 0.9 & & \\
\hline \multicolumn{10}{|c|}{ DNA binding/signal transduction } \\
\hline C278 & A201 & Q09028 & Retinoblastoma binding protein 4 variant & 47,910 & 4.74 & 67 & 1.1 & & \\
\hline C400 & A299 & P06748 & Nucleophosmin & 32,653 & 4.64 & 76 & 1.3 & & $\mathrm{x}$ \\
\hline C463 & A350 & P12004 & Pcna & 29,156 & 4.57 & 154 & 2.5 & & $\mathrm{x}$ \\
\hline \multirow[t]{2}{*}{ C424 } & A321 & P22626 & Heterogeneous nuclear ribonucleoproteins (hnRNP) A2/B1 & 37,464 & 8.97 & 95 & 2.2 & & $\mathrm{x}$ \\
\hline & A541 & P62158 & Calmodulin & 17,152 & 4.09 & 48 & AZA & $\mathrm{x}$ & \\
\hline
\end{tabular}

Acression number by UniProtKB.

b Accession number by UniProtKB.
MWeoretical molecular weigh obtained by ExPASy Proteomic Server.

c $\mathrm{pI}$ - theoretical isoelectric point obtained by ExPASy Proteomic Server

d Score - index calculated by MASCOT-significant when greater than $56(p<0.05)$.

e Ratio between spot volume in CTRL and spot volume in treated gels. 
Table 2

Differentially expressed proteins identified by mass spectrometry after decitabine treatment.

\begin{tabular}{|c|c|c|c|c|c|c|c|c|c|}
\hline Spot CTRL & Spot DAC & $\begin{array}{l}\text { Accession } \\
\text { number }^{\mathrm{a}}\end{array}$ & Heat Shock Proteins/Chaperons & $\mathrm{MW}^{\mathrm{b}}$ & $\mathrm{pl}^{\mathrm{c}}$ & Score $^{d}$ & Vol. C/Vol. De & $\begin{array}{l}\text { Induced or } \\
\text { overexpressed by DAC }\end{array}$ & $\begin{array}{l}\text { Inhibited or } \\
\text { reduced by DAC }\end{array}$ \\
\hline C1591 & D43 & P07900 & Heat shock protein $90 \mathrm{kDa}$ alpha (cytosolic), class B member $1^{*}$ & 83,638 & 4.94 & 89 & 1.4 & & $\mathrm{x}$ \\
\hline C1609 & D66 & P07900 & Heat shock protein $90 \mathrm{kDa}$ alpha (cytosolic), class B member $1^{*}$ & 83,638 & 4.94 & 85 & 2.3 & & $\mathrm{X}$ \\
\hline C1614 & D73 & P07900 & Heat shock protein $90 \mathrm{kDa}$ alpha (cytosolic), class B member $1^{*}$ & 83,638 & 4.94 & 93 & 0.2 & $\mathrm{x}$ & \\
\hline C1689 & D157 & P10809 & Heat shock protein 60 & 61,388 & 5.24 & 147 & 1.6 & & $\mathrm{x}$ \\
\hline C1651 & D119 & P11142 & Heat shock $70 \mathrm{kDa}$ protein $8^{*}$ & 71,138 & 5.37 & 161 & 1.3 & & $\mathrm{x}$ \\
\hline $\mathrm{C} 2315$ & D71 & P11142 & Heat shock $70 \mathrm{kDa}$ protein $8^{*}$ & 71,138 & 5.37 & 101 & 0.5 & $\mathrm{x}$ & \\
\hline C1674 & D155 & P27797 & Calreticulin & 48,283 & 4.28 & 90 & 4.6 & & $\mathrm{x}$ \\
\hline C1713 & D184 & P30101 & Protein-disulfide isomerase $\mathrm{A} 3^{*}$ & 56,747 & 5.61 & 82 & 1.5 & & $\mathrm{x}$ \\
\hline C1768 & D251 & P30101 & Protein-disulfide isomerase $\mathrm{A}^{*}{ }^{*}$ & 57,146 & 5.61 & 72 & 2.2 & & $\mathrm{x}$ \\
\hline C1752 & D225 & P30101 & Protein-disulfide isomerase $\mathrm{A}^{*}$ & 57,146 & 5.61 & 88 & 1.2 & & $\mathrm{X}$ \\
\hline C2007 & D660 & P30040 & Endoplasmic reticulum protein ERp29 & 29,032 & 6.08 & 70 & 1.8 & & $\mathrm{X}$ \\
\hline C2119 & D565 & P23284 & Cyclophilin B & 22,785 & 9.25 & 122 & 1.3 & & $\mathrm{x}$ \\
\hline C2178 & & P62937 & Cyclophilin A* & 18,229 & 7.82 & 61 & CTRL & & $\mathrm{x}$ \\
\hline C2183 & D606 & P62937 & Cyclophilin A* & 18,229 & 7.82 & 75 & 0.4 & $\mathrm{x}$ & \\
\hline C2184 & D612 & P62937 & Cyclophilin $\mathrm{A}^{*}$ & 18,229 & 7.82 & 91 & 1.4 & & $\mathrm{x}$ \\
\hline C1732 & D204 & P78371 & Chaperonin containing TCP1, subunit 2 (beta) & 57,878 & 6.02 & 125 & 1.3 & & $\mathrm{x}$ \\
\hline \multicolumn{10}{|l|}{ Enzymes } \\
\hline C1824 & D283 & P00558 & Phosphoglycerate kinase 1 & 44,985 & 8.30 & 100 & 3.9 & & $\mathrm{X}$ \\
\hline C1875 & D347 & P06733 & Alpha-Enolase* & 47,481 & 6.99 & 121 & 2.4 & & $\mathrm{x}$ \\
\hline \multirow[t]{2}{*}{ C1778 } & D237 & P06733 & Alpha-Enolase* & 47,481 & 6.99 & 195 & 2.1 & & $\mathrm{x}$ \\
\hline & D256 & P07954 & Fumarate hydratase, mitochondrial & 54,773 & 6.99 & 55 & DAC & $\mathrm{x}$ & \\
\hline C1707 & D160 & P04040 & Catalase & 59,947 & 6.95 & 62 & 0.8 & $\mathrm{x}$ & \\
\hline C1925 & D403 & Q15181 & Inorganic pyrophosphatase & 33,095 & 5.54 & 120 & 1.6 & & $\mathrm{x}$ \\
\hline C1927 & D402 & Q15181 & Inorganic pyrophosphatase & 33,095 & 5.54 & 108 & 1.4 & & $\mathrm{x}$ \\
\hline C1970 & D424 & P14207 & Folate receptor beta & 30,286 & 7.47 & 32 & 0.6 & $\mathrm{x}$ & \\
\hline C2142 & D593 & Q8TAE6 & Protein phosphatase 1 regulatory subunit $14 \mathrm{C}$ & 17,946 & 5.09 & 31 & 0.8 & $\mathrm{x}$ & \\
\hline C1900 & D363 & P04406 & Glyceraldehyde-3-phosphate dehydrogenase & 36,201 & 8.58 & 59 & 1.5 & & $\mathrm{x}$ \\
\hline C2037 & D489 & P60174 & Chain B, Triosephosphate Isomerase (Tim) & 26,877 & 6.51 & 155 & 1.2 & & \\
\hline C1693 & D137 & Q02318 & Cytocrome P450 27, mitochondrial & 60,595 & 8.43 & 27 & 0.8 & $\mathrm{x}$ & \\
\hline \multicolumn{10}{|c|}{ Cell redox homeostasis } \\
\hline C2060 & D522 & P09211 & Glutathione S-transferase P & 23,569 & 5.44 & 58 & 1.4 & & $\mathrm{x}$ \\
\hline C2072 & D531 & Q06830 & Peroxiredoxin-1 & 22,324 & 8.27 & 81 & 2.3 & & $\mathrm{x}$ \\
\hline C1848 & D331 & 076003 & Glutaredoxin-3 & 37,693 & 5.31 & 83 & 2.0 & & $\mathrm{x}$ \\
\hline \multicolumn{10}{|c|}{ Structural proteins } \\
\hline C2323 & D304 & P60709 & ACTB protein (Beta-actin) & 40,620 & 5.29 & 163 & 1.9 & & $\mathrm{x}$ \\
\hline C1906 & D375 & P07437 & Beta tubulin* & 48,233 & 4.78 & 154 & 1.7 & & $\mathrm{x}$ \\
\hline C1915 & D391 & P07437 & Beta tubulin* & 48,233 & 4.78 & 58 & 1.1 & & $\mathrm{x}$ \\
\hline C2269 & D205 & P68363 & Alpha tubulin & 50,972 & 4.94 & 89 & 0.3 & $\mathrm{x}$ & \\
\hline \multicolumn{10}{|c|}{ DNA binding/signal trasduction } \\
\hline C1995 & D459 & P35232 & Prohibitin & 29,843 & 5.57 & 142 & 1.6 & & $\mathrm{x}$ \\
\hline C1933 & D412 & P12004 & Pcna & 29,156 & 4.57 & 127 & 0.8 & $\mathrm{x}$ & \\
\hline C1888 & D345 & Q13347 & Eukaryotic translation initiation factor 3 subunit I & 36,878 & 5.38 & 92 & 1.8 & & $\mathrm{x}$ \\
\hline C1926 & D394 & P22626 & Heterogeneous nuclear ribonucleoproteins A2/B1 & 37,464 & 8.97 & 112 & 1.4 & & $\mathrm{x}$ \\
\hline C1940 & D388 & P09651 & Heterogeneous nuclear ribonucleoprotein A1 & 38,936 & 9.17 & 132 & 1.4 & & $\mathrm{x}$ \\
\hline C1834 & D307 & P29992 & Guanine nucleotide-binding protein subunit alpha- 11 & 42,382 & 5.51 & 54 & 2.0 & & $\mathrm{x}$ \\
\hline C2035 & D491 & P52565 & Rho GDP-dissociation inhibitor 1 & 23,250 & 5.03 & 80 & 1.4 & & $\mathrm{x}$ \\
\hline C1862 & D336 & P06748 & Nucleophosmin & 32,653 & 4.64 & 64 & 0.9 & $\mathrm{x}$ & \\
\hline C1841 & D320 & Q9Y3F4 & Serine-threonine kinase receptor-associated protein & 38,756 & 4.98 & 51 & 0.6 & $\mathrm{x}$ & \\
\hline C2160 & & P62158 & Calmodulin & 17,152 & 4.09 & 49 & CTRL & & $\mathrm{x}$ \\
\hline
\end{tabular}

a Accession number by UniProtKB.

b MW - theoretical molecular weigh obtained by ExPASy Proteomic Server.

c $\mathrm{pI}$ - theoretical isoelectric point obtained by ExPASy Proteomic Server.

d Score - index calculated by MASCOT-significant when greater than $56(p<0.05)$.

e Ratio between spot volume in CTRL and spot volume in treated gels. 
A
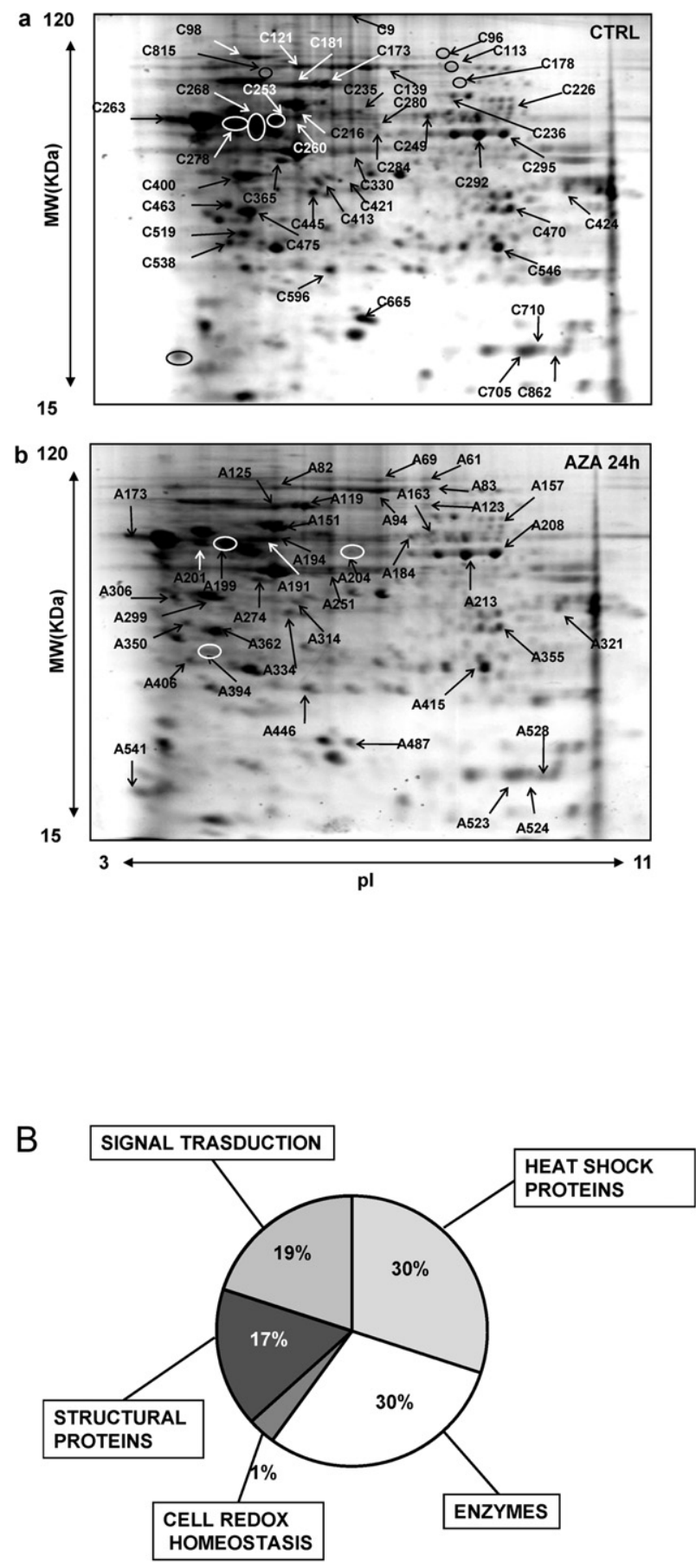

C
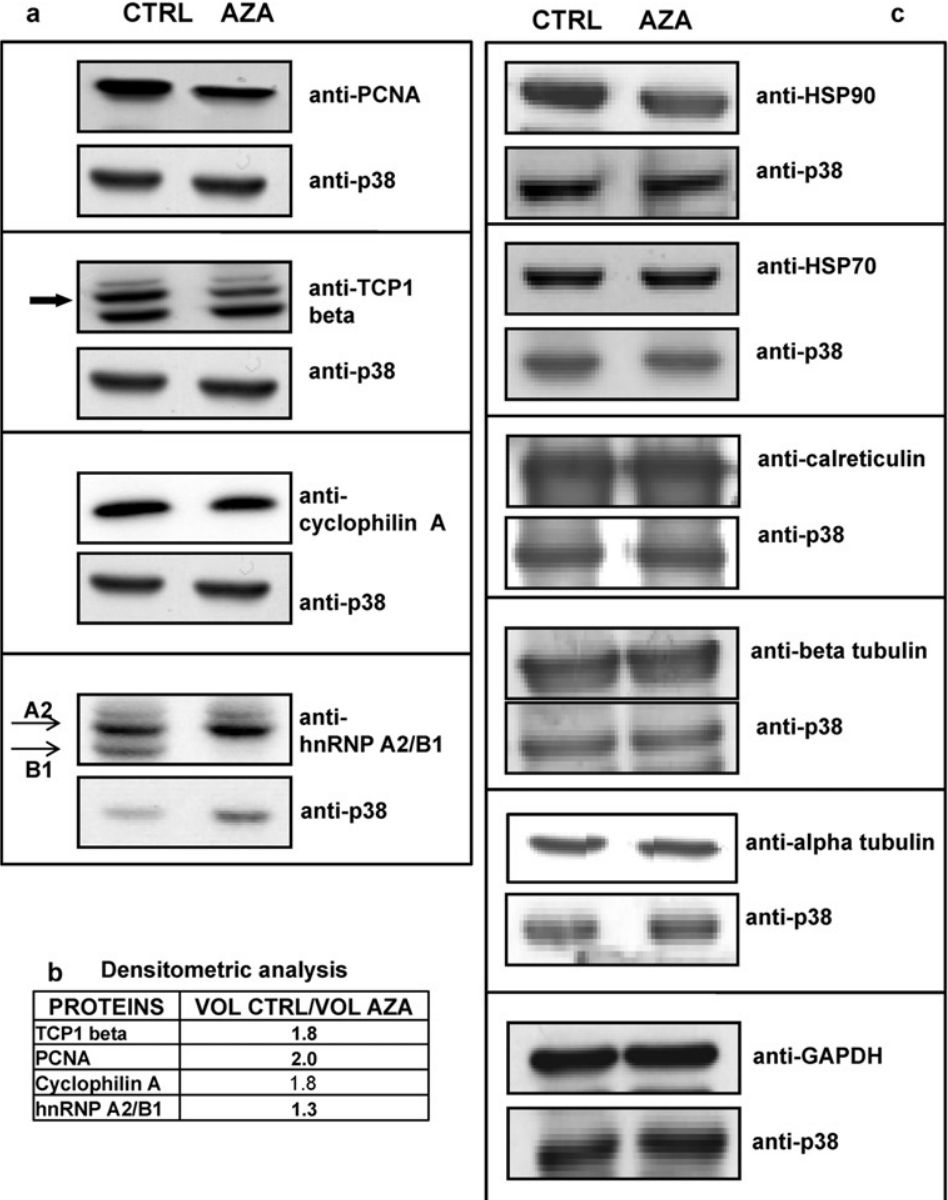

D

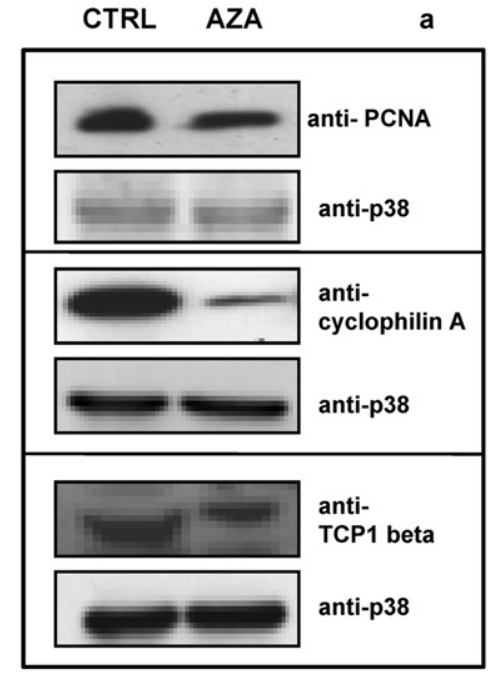

CTRL AZA DAC b

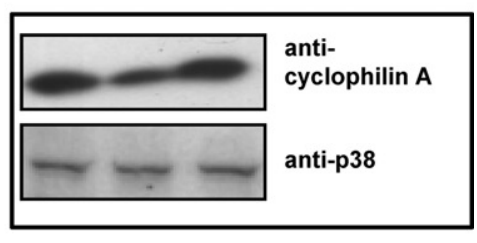

\# 2

\section{\# 1}

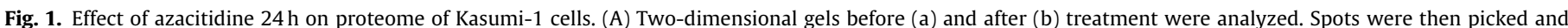

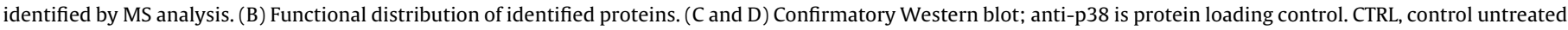
cells; AZA, azacitidine; DAC, decitabine.

were found; 50 protein spots had significant differences between untreated control and decitabine treated cells. We excised 36 protein spots from control gel and 14 spots from treated gel; mass spectrometry analysis MALDI-TOF allowed us to identify 45 spots corresponding to 35 characteristic proteins (Fig. 2A, a and b), classified in functional categories by David Bioinformatics database.
Results were reported in Table 2 (spot number obtained from Image Master, correlate to corresponding spots in Fig. 2A).

As shown in Fig. 2B, nine proteins (26\%) identified by MS included molecules functionally classified as Heat Shock Proteins/Chaperons, ten proteins (29\%) were enzymes, most of which metabolic, three proteins $(9 \%)$ were involved in stress/redox 
A
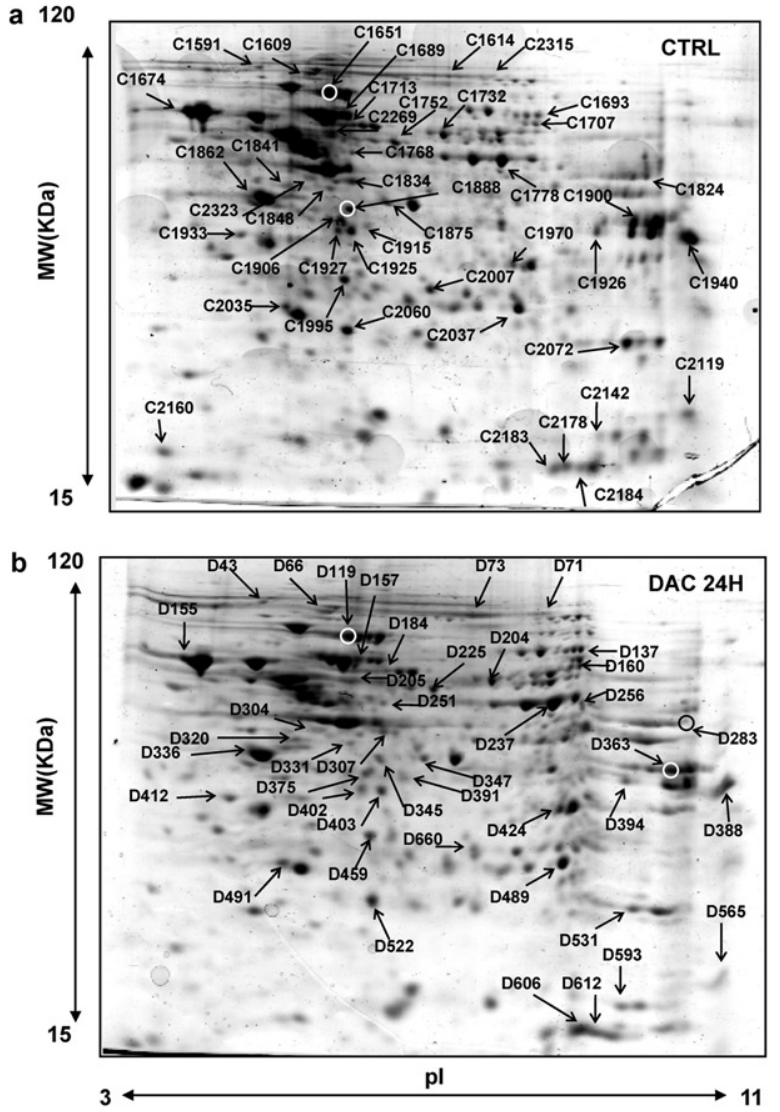

B

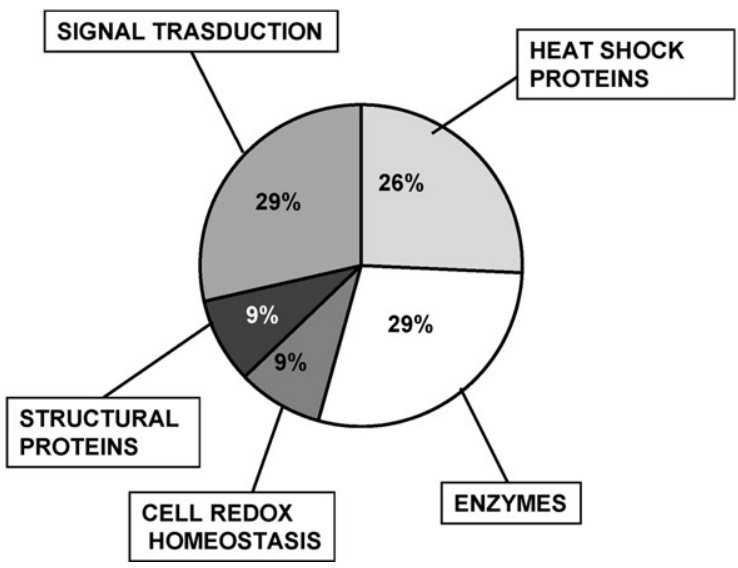

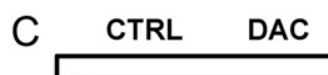

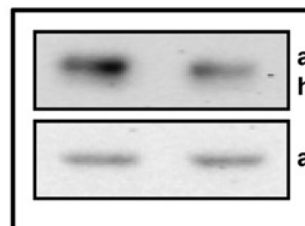

antihnRNP A2/B1

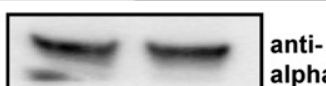

anti- p38

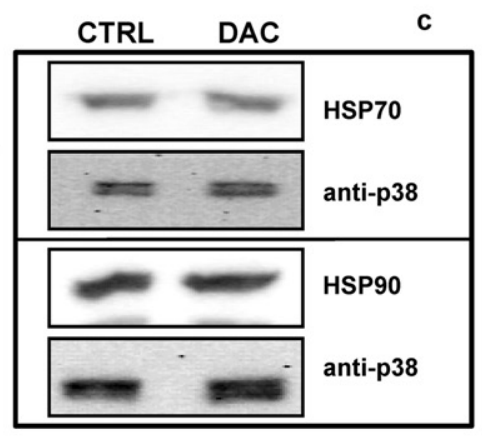

a

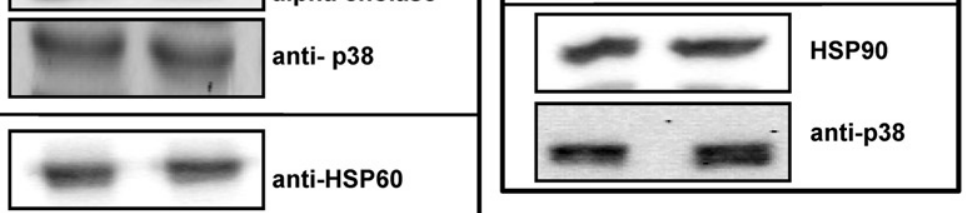

b Densitometric analysis

\begin{tabular}{|l|c|}
\hline \multicolumn{1}{|c|}{ PROTEINS } & VOL CTRL/VOL DAC \\
\hline hnRNP A2/B1 & 1.5 \\
\hline alpha Enolase & 1.2 \\
\hline HSP 60 & 0.4 \\
\hline cyclophilin-a & 0.8 \\
\hline alpha Tubulin & 0.4 \\
\hline
\end{tabular}

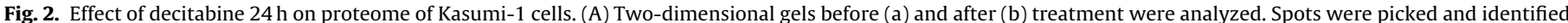

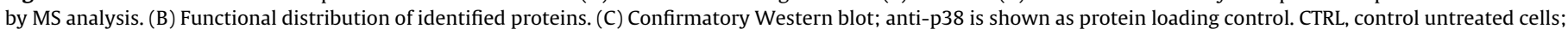
DAC, decitabine.

homeostasis, three $(9 \%)$ were structural proteins and ten proteins $(29 \%)$ were involved in signal transduction (Table 1 and Supplementary data). After decitabine treatment, the majority of identified proteins (those selected on the basis of a significant modulation in expression) were down-regulated, although protein spot number did not decrease (Table 2).

String analysis showed that the majority of modulated proteins were correlated (Fig S2, b - Supplementary data). Decrease of hnRNP A2/B1, alpha-Enolase and the increase of Cyclophilin A, HSP60 (ratio of densitometry CTRL/AZA: 0.4, respect to control loading p38) and alpha-Tubulin were confirmed (Fig. 2C, a and b). Several proteins (HSP90, HSP70, PDIA3, Cyclophilin A,
beta-Tubulin, alpha-Enolase) had different migration sites into both 2D gels (Table 2 - marked with an asterisk), because of their isoforms (see above), so some of these did not change the global expression (Fig. 2C, c).

Cyclophilin A expression was increased in primary $t(8 ; 21)$ AML cells after $24 \mathrm{~h}$ exposure to decitabine in vitro (Fig. 1D, b).

\subsection{Comparison between AZA and DAC treatments}

We matched gels after treatment with azacitidine and decitabine, in order to identify commonly modulated proteins and to evaluate possible different effects of the two agents on 

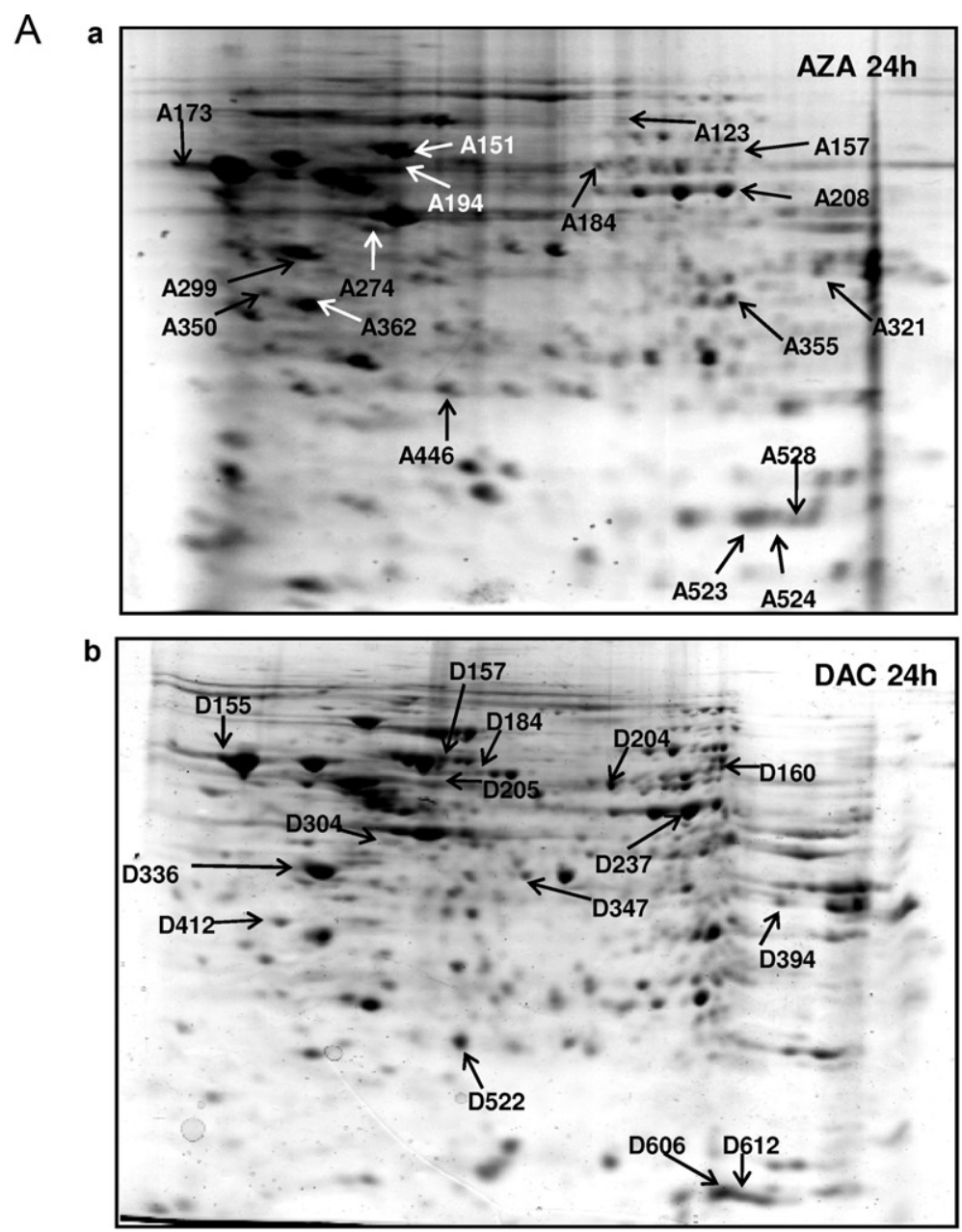

\begin{tabular}{|c|c|c|c|c|}
\hline $\begin{array}{c}\text { SPOT } \\
\text { AZA }\end{array}$ & \begin{tabular}{|l} 
SPOT \\
DAC
\end{tabular} & PROTEIN NAME & AFTER AZA & AFTER DAC \\
\hline & & HEAT SHOCK PROTEINS/CHAPERONS & & \\
\hline A151 & D157 & Heat shock protein 60 & NO CHANGE & DECREASE \\
\hline A184 & D204 & Chaperonin containing TCP1, subunit 2 (beta) & DECREASE & DECREASE \\
\hline A528 & & \multirow{3}{*}{ Cypa (Cyclophilin A) } & \multirow{3}{*}{ DECREASE } & \multirow{3}{*}{ INCREASE } \\
\hline A524 & $\mathbf{D 6 1 2}$ & & & \\
\hline A523 & DEO6 & & & \\
\hline & D184 & PDIA3 & DECREASE & DECREASE \\
\hline A173 & D155 & Calreticulin & DECREASE & DECREASE \\
\hline & & ENZYMES & & \\
\hline A208 & D237 & Alpha Enolase & NO CHANGE & DECREASE \\
\hline A355 & D363 & Glyceraldehyde-3-phosphate dehydrogenase & DECREASE & DECREASE \\
\hline \multirow[t]{2}{*}{ A157 } & D160 & Catalase & DECREASE & NOCHANGE \\
\hline & & CELL REDOX HOMEOSTASIS & & \\
\hline \multirow[t]{2}{*}{ A446 } & D522 & Glutathione S-transferase P & DECREASE & DECREASE \\
\hline & & $\begin{array}{l}\text { STRUCTURAL PROTEINS } \\
\end{array}$ & & \\
\hline A194 & D205 & Alpha tubulin & NOCHANGE & INCREASE \\
\hline \multirow[t]{2}{*}{ A274 } & D304 & ACTB protein (Beta-actin) & DECREASE & DECREASE \\
\hline & & DNA BINDING /SIGNAL TRANSDUCTION & & \\
\hline A299 & A336 & Nucleophosmin & DECREASE & NOCHANGE \\
\hline А 350 & D412 & Pcna & DECREASE & NOCHANGE \\
\hline A321 & D394 & Heterogeneous nuclear ribonucleoproteins A2/B1 & DECREASE & DECREASE \\
\hline
\end{tabular}

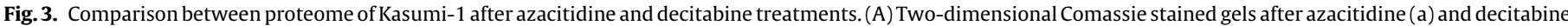
(b) were compared and common proteins identified. (B) Table of common proteins. AZA, azacitidine; DAC, decitabine. 


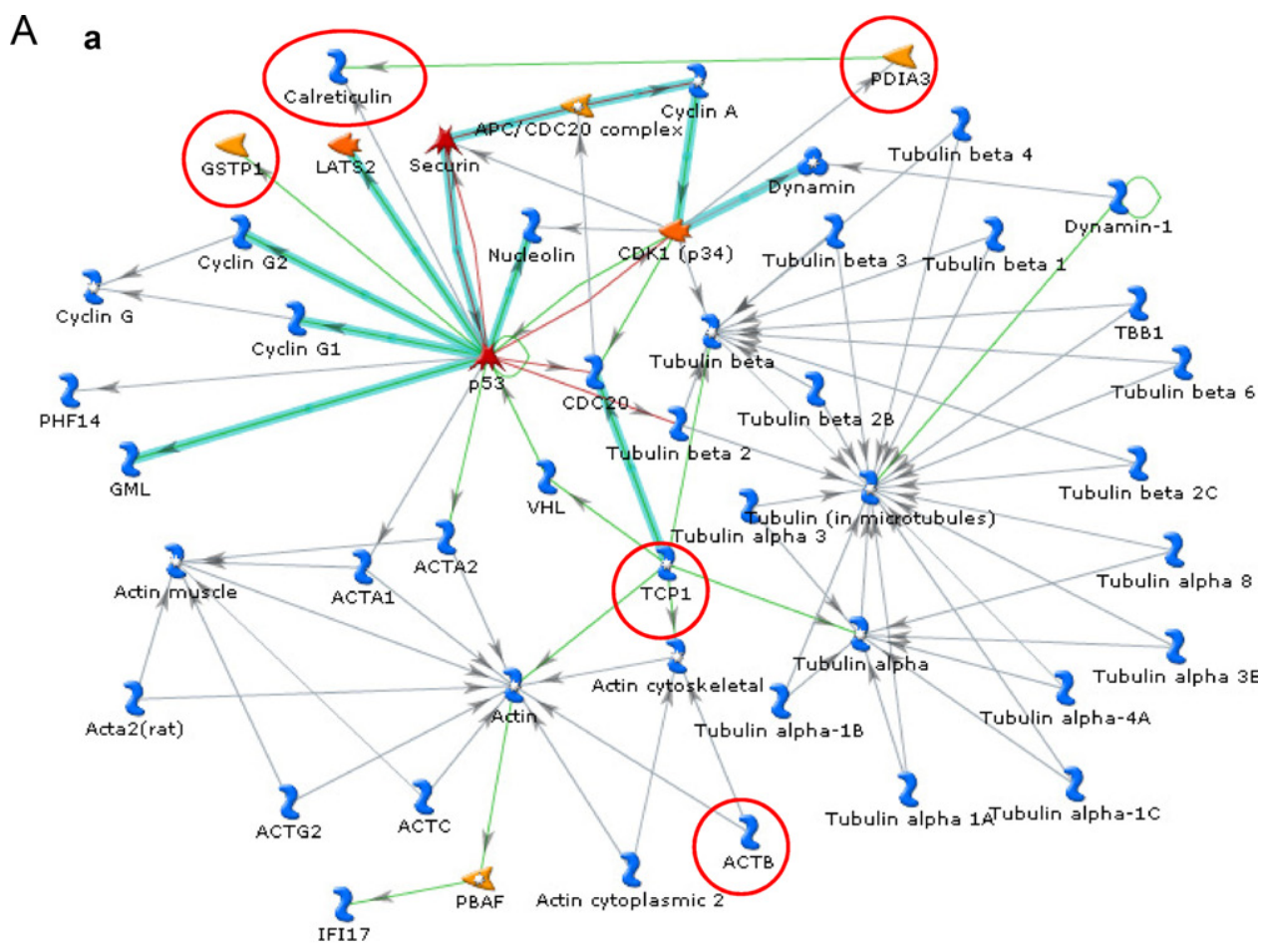

\begin{tabular}{|c|c|c|}
\hline $\begin{array}{c}\text { Key network } \\
\text { objects }\end{array}$ & GO Processes & $\begin{array}{l}\text { Total Seed Path p-Val } \\
\text { nodes nodes ways ue }\end{array}$ \\
\hline $\begin{array}{l}\text { TCP1, PBAF, } \\
\text { Calreticulin, } \\
\text { PDIA3, GSTP1 }\end{array}$ & $\begin{array}{l}\text { 'de novo' posttranslational protein folding }(40.0 \%) \text {, 'de novo' } 5 \\
\text { protein folding }(40.0 \%) \text {, protein polymerization }(36.0 \%) \text {, } \\
\text { protein folding }(46.0 \%) \text {, microtubule-based movement }(36.0 \%)\end{array}$ & $\begin{array}{rll}50 \quad 6 \quad 6 \quad 1.38 \mathrm{e}- \\
& 16\end{array}$ \\
\hline
\end{tabular}

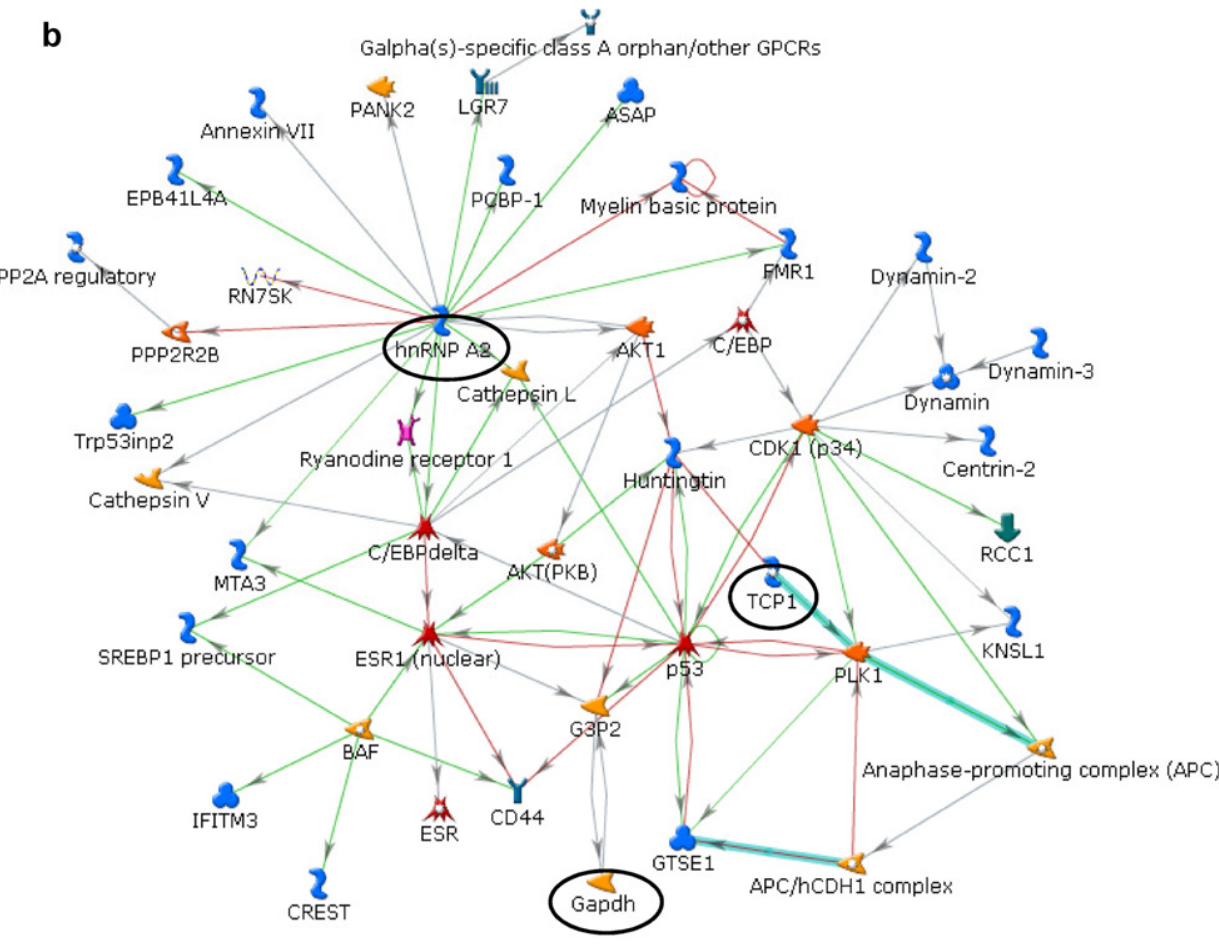

\begin{tabular}{|c|c|c|}
\hline Key n & GO Processes & Total Seed Path p-Val \\
\hline $\begin{array}{l}\text { hnRNPA2, } \\
\text { BAF, G3P2, } \\
\text { TCP1, p53 }\end{array}$ & $\begin{array}{l}\text { regulation of cell cycle process }(26.7 \%) \text {, cell cycle process } \\
(35.6 \%) \text {, regulation of mitotic cell cycle }(24.4 \%) \text {, mitotic cell } \\
\text { cycle }(31.1 \%) \text {, cell cycle }(37.8 \%)\end{array}$ & $\begin{array}{l}1.04 \mathrm{e}^{-} \\
10\end{array}$ \\
\hline
\end{tabular}

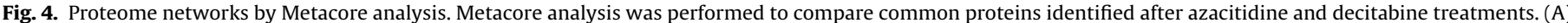

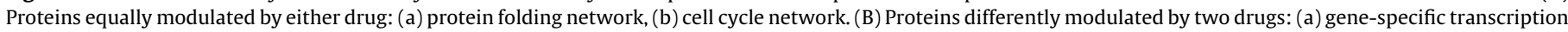
network, (b) response to stress-network. (C) Cyclophilin A pathway network. 


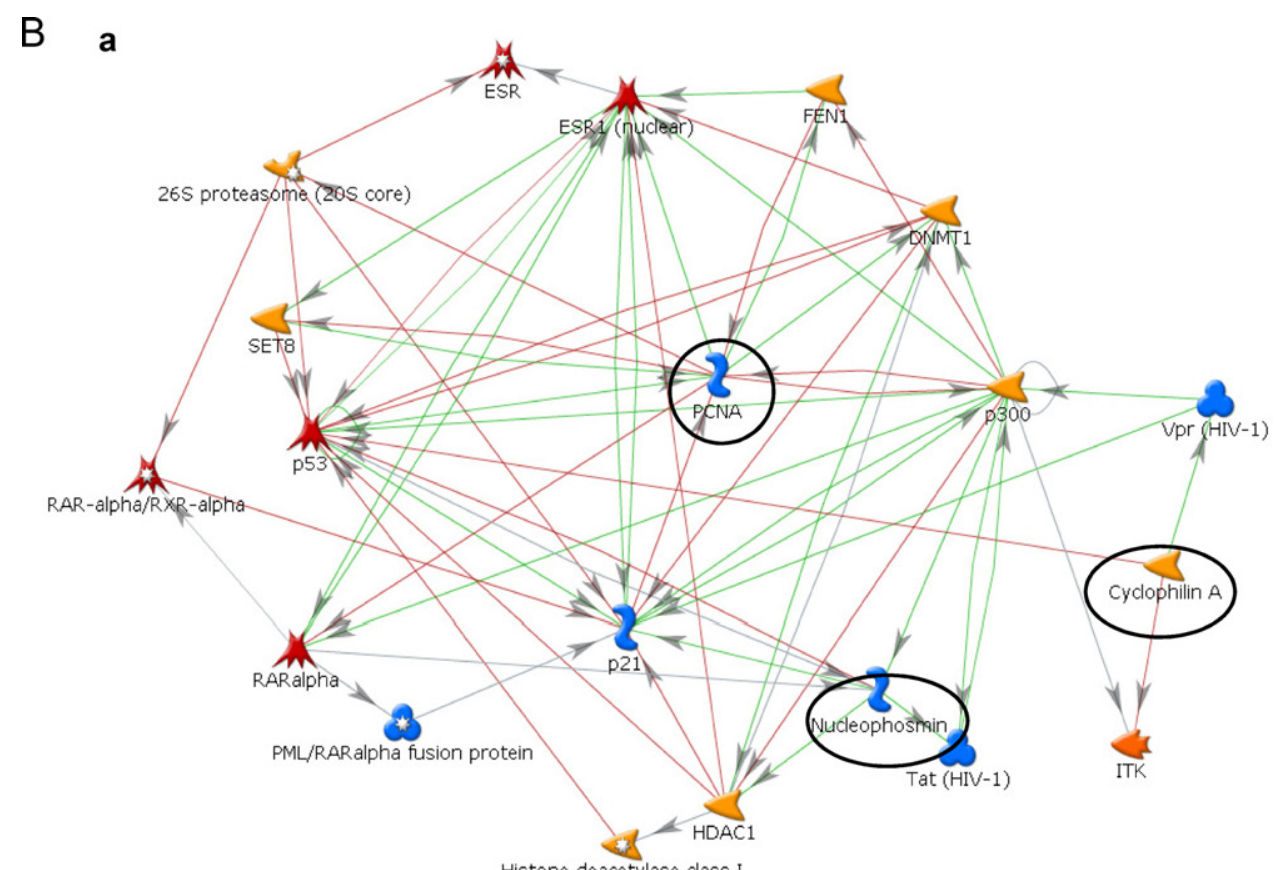

Histone deacetylase class I
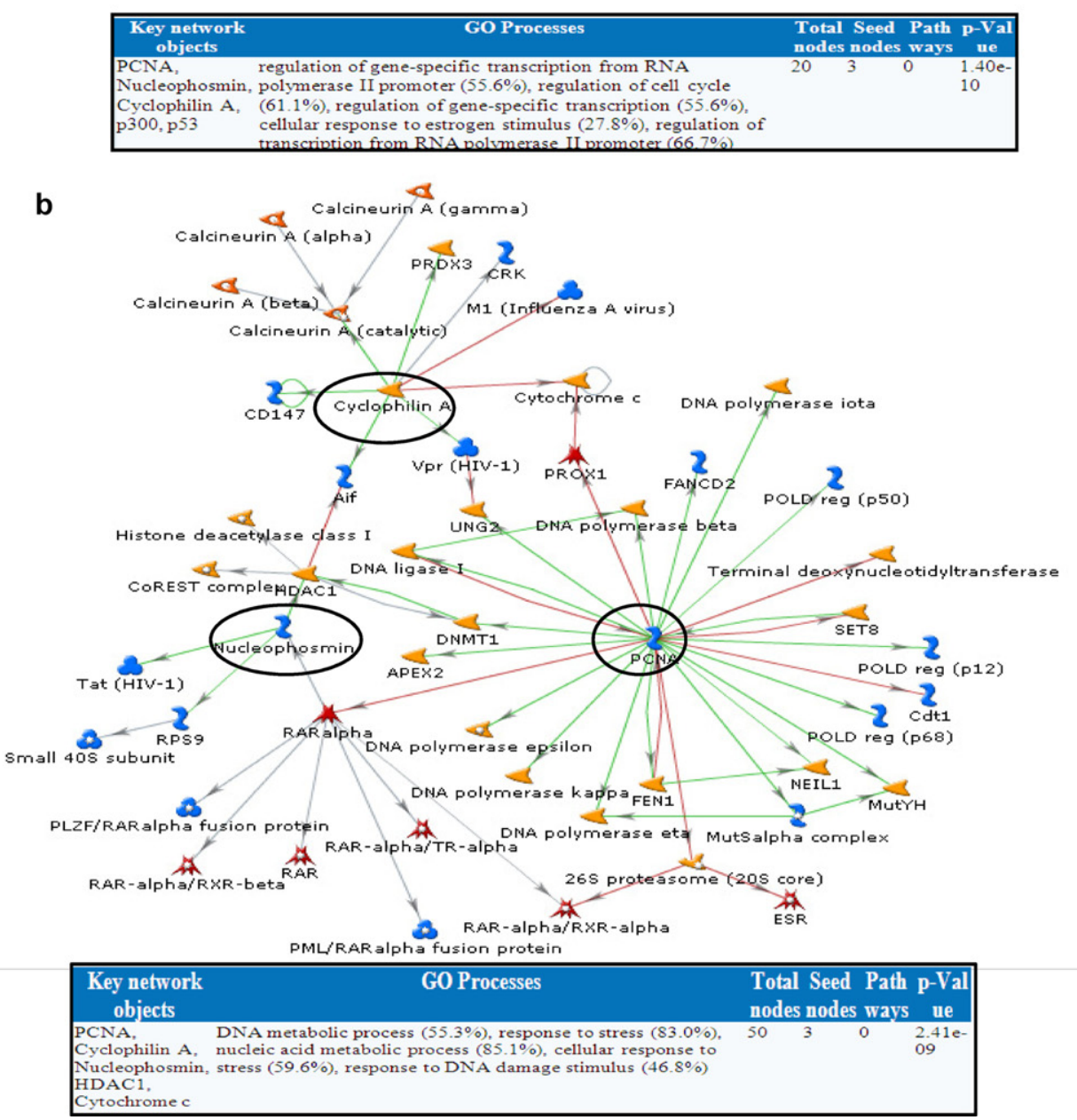

Fig. 4. (continued) 


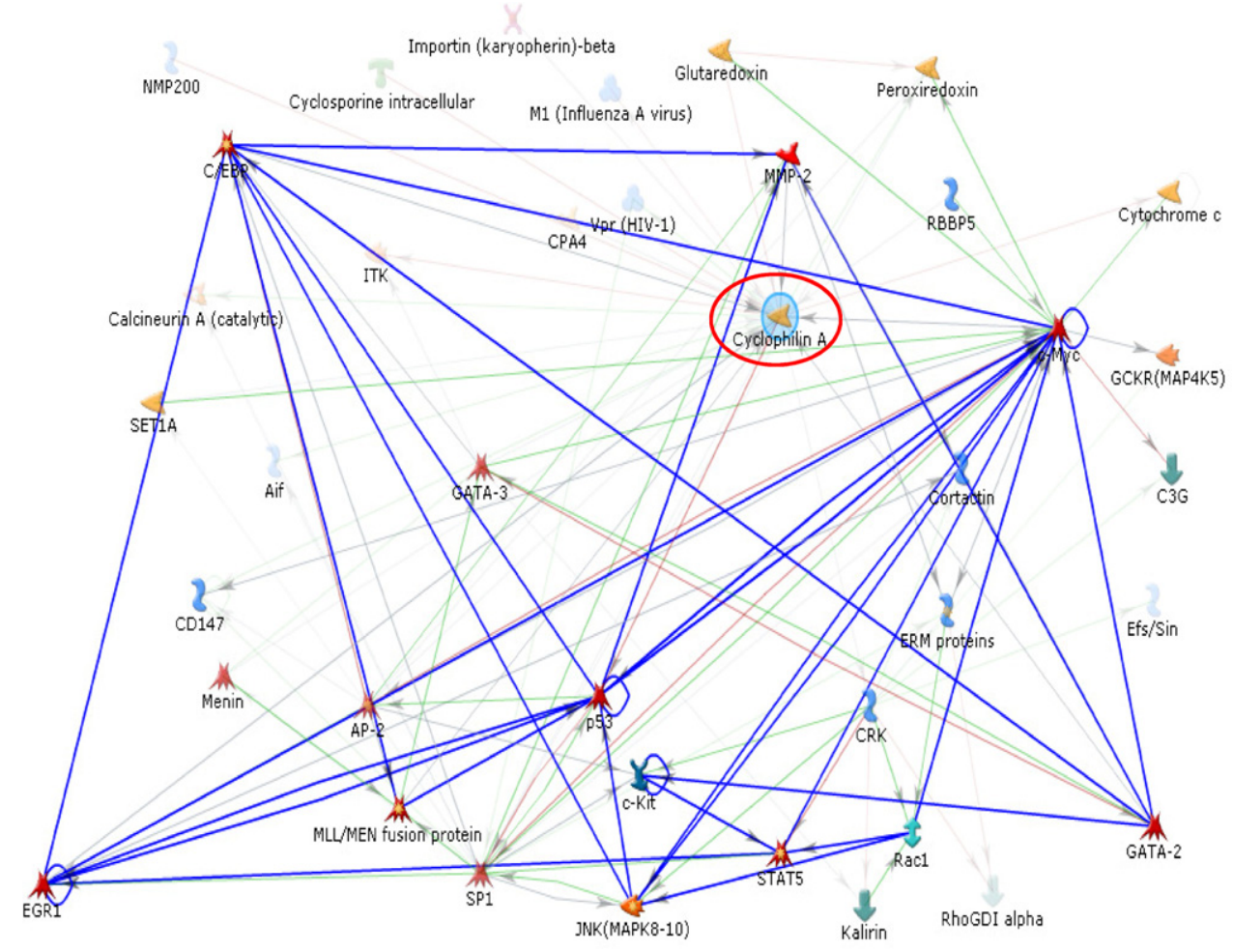

Fig. 4. (continued)

protein expression (Fig. 3A, a and b). Considering only proteins with a significant MASCOT score (Tables 1 and 2; score $>56$ ), and those proteins whose global expression (summing isoforms) was modulated, we found 14 proteins identified both in azacitidine and decitabine treated gels (Fig. 3B).

\subsection{Protein network analysis}

A pattern analysis was performed using the software MetaCore ${ }^{\mathrm{TM}}$ in order to evaluate the possible correlation between the 2D-electrophoresis/MS identified modulated proteins and possible cellular pathways affected by azacitidine and decitabine (Table 3). This analysis allowed also to relate the function of single proteins to the cellular context. All proteins analyzed were processed by the "network analysis" algorithm with fifty nodes, which generates sub-networks ranked by $p$-values.

First of all, we investigated the correlation between proteins that were equally modulated by either drug, particularly TCP1 beta, PDIA3, Calreticulin, Glyceraldehyde-3-phosphate dehydrogenase (GAPDH), Glutathione S-transferase P, ACTB and hnRNPA2/B1 (Fig. 3B). The analysis clustered proteins in two networks: the first, which include TCP1, Calreticulin, ACTB, PDIA3 and GSTP1 regulates protein folding (Fig. 4A, a) and the second, which includes GAPDH, Tcp1 and hnRNP A2/B1, modulates cell cycle (Fig. 4A, b).

Among proteins that had different modulation after two drugs treatments, we focused our analysis on proteins decreased only by azacitidine (Fig. 3B), particularly Cyclophilin A, Catalase, Nucleophosmin and PCNA. This analysis lead to cluster proteins in three network: two, including PCNA, Nucleophosmin and Cyclophilin A, are involved in gene-specific transcription and in response to stress (Fig. 4B, a and b), the third one is identified via Catalase presence, involved in triglyceride metabolism.

Since Cyclophilin A showed a decrease of expression after azacitidine and an increase after decitabine, we analyzed its pathway network as an interesting difference between the two agents. It seems particularly relevant that Cyclophilin A is involved in AML proliferation and maintenance (Fig. 4C - links marked in blue).

\section{Discussion}

Azacitidine and decitabine are used for treatment of MDS and AML. Although these two agents share a similar chemical structure and are often considered equivalent, they exert divergent biological effects and have some different clinical activity, as only azacitidine has been shown to significantly improve survival in MDS [14] while decitabine seems to have preferential activity on CMML [15] and AML [11]. Part of the differences may be due to prevalent incorporation into RNA of azacitidine and into DNA of decitabine, but it appears that other effects, beside hypomethylation, may explain their clinical activity [16]. Characterization of azacitidine and decitabine effects on protein expression, protein networks and pathways may help in understanding their molecular

Table 3

Summary of proteome modifications after azacitidine and decitabine treatment of AML1/ETO positive leukemic cells.

\begin{tabular}{|c|c|c|c|c|c|}
\hline Drug & Number of protein spots & Proteins modulated & & & \\
\hline AZA & Decrease & $\begin{array}{l}\downarrow 5 \text { involved in protein folding } \\
\downarrow 3 \text { involved in cell cycle }\end{array}$ & $\begin{array}{l}\downarrow 3 \text { involved in gene-specific transcription } \\
\downarrow 3 \text { involved in response to stress } \\
\downarrow \text { Catalase }\end{array}$ & & \\
\hline DAC & No change & $\begin{array}{l}\downarrow 5 \text { involved in protein folding } \\
\downarrow 3 \text { involved in cell cycle }\end{array}$ & & $\begin{array}{l}\uparrow \text { Cyclophilin A } \\
\uparrow \text { Catalase }\end{array}$ & $\downarrow$ alpha-Enolase \\
\hline
\end{tabular}


mechanisms, whose discrepancies have started to be highlighted in scientific literature $[3,5,6]$. AML1/ETO positive leukemias have a particular good prognosis and are sensitive to chemotherapy [7-10]. Most interestingly, the AML1/ETO complex binding DNMTs and HDAC forms a putative ideal target for epigenetic drugs [7-10]. We employed a sensitive, 2D-electrophoresis approach followed by MALDI-TOF/MS to investigate proteins modifications after short term in vitro treatment with azacitidine and decitabine. This proteomic approach is increasingly used to implement studies of mechanisms of action of drugs [17,18].

We could demonstrate distinct expression pattern between protein extracts from untreated leukemic cells and extracts from azacitidine and decitabine treated cells. Specific proteins were significantly down-regulated, although not completely, by both drugs. We focused our attention both on the commonly repressed proteins, and on those decreased exclusively by one agent, to verify whether this difference could justify the diverse clinical effects of the two DNMT inhibitors. Quite differently from azacitidine, decitabine did not decrease the global number of protein spots, respect to untreated samples. This is consistent with the lack of inhibition of protein synthesis by decitabine, observed by other authors with different analytical methods [3].

The two published reports on gene expression modification by DNMT inhibitors [5,6] do not identify the same set of genes, and there is no significant overlap with our protein findings either.

Although the two agents are supposed to act and be efficient in clinics via hypomethylation of $\mathrm{CpG}$ islands of gene promoters, the majority of modulated proteins by in vitro DNMT inhibitors treatment were repressed, similarly to what observed in gene expression studies [6]. Moreover, we could not detect significant increase of tumor suppressor genes, indicating, again similarly to what already observed by other authors, that although the genes of these proteins may be up regulated via hypomethylation to levels detectable by PCR-based methods, they are not part of the general dominant expression pattern induced by these drugs, and proteomic methods are not sensitive enough to detect them [5].

In order to better understand the relationships among the proteins identified, we used String database, as well as MetaCore ${ }^{\mathrm{TM}}$. Most of the proteins whose expression was modified by DNMT inhibitors were inter-related in the pathway map, confirming the biological reliability of our analysis. In addition, the majority of modulated proteins were known to be involved in neoplastic progression, so that their decreased expression by DNMT inhibitors may help to understand the mechanisms by which these agents exert their anticancer activity.

In the MetaCore ${ }^{\mathrm{TM}}$ produced network, the identified proteins clustered in two networks, one modulating protein folding and polymerization (TCP1, PBAF, Calreticulin, PDIA3, GSTP1) and the second involved in regulation of cell cycle and mitosis and RNA transport (hnRNPA2, BAF, G3P2, TCP1).

The Chaperonin Containing TCP1 in the eukaryotic cytosol ensures the correct folding and assembly of a variety of proteins. Neoplastic cells show an overexpression of TCP1 beta [19]. In our model, azacitidine and decitabine provoked decrease in TCP1 expression, and also a decrease in its best-characterized substrate beta-actin. We could indeed confirm this finding also in primary AML cells. Calreticulin is increased in several neoplastic diseases [20], and its expression decreased after both DNMTi treatments. The same inhibition is observed for Glutathione S-transferases (GSTs), which are a family of enzymes that catalyze the conjugation of glutathione (GSH) to various xenobiotics and participate in cellular protection against oxidative stress or resistance to drugs. These proteins exhibit genetic polymorphisms in their population distribution, and these variants are frequently expressed in AML patient and may influence their prognosis [21,22].
Heterogeneous ribonucleoproteins (hnRNPs) are complexes of RNA and protein present in the cell nucleus during gene transcription and subsequent post-transcriptional modification of the newly synthesized RNA (pre-mRNA). They are involved in splicing of pre-mRNA and in its transport out of the nucleus. Overexpression of hnRNP A2/B1 is correlated to cancer progression [23], particularly hnRNP B1 is over-expressed in MDS and AML-MDS [24] while hnRNP A1 is over expressed generally in solid [25] and hematological malignances [26]. From our analysis, it emerged that both agents, in our experimental conditions, have the same inhibiting activity on cell cycle/RNA metabolism and protein folding. Effects on gene expression and miRNA expression have been demonstrated to be time dependent, but we privileged the analysis of early modulation by these two drugs, to possibly examine non cytotoxic effects [5].

Regarding proteins selectively modulated by azacitidine, it looks quite important that one cluster of decreased proteins (PCNA, Cyclophilin A, NPM-1) is involved in response to stress, suggesting a role of azacitidine in impairing reaction of leukemic cells to DNA damage. The same proteins are regulating gene-specific transcription, and azacitidine could influence it, but not necessarily by $\mathrm{CpG}$ island hypomethylation. Besides, only azacitidine inhibits Catalase, which not only protects cells from the toxic effects of hydrogen peroxide, but also promotes growth of myeloid leukemia cells, thanks to ERK-1 activation [27]. In conclusions, azacitidine, but not decitabine, seemingly exerts an important down regulation of anti-stress proteins.

Cyclophilin A (CypA) modulation is quite peculiar, because its expression is reduced by azacitidine, but increased by decitabine, and these results were confirmed also in primary human $t(8 ; 21)$ AML cells. Recent studies indicated different possible roles of CypA in tumor development, given that its expression resulted increased and induced by c-Myc and it has inhibitory activity on p53, as also shown by our analysis with MetaCore. This discrepancy after drug treatment could be consistent with a reported early and transient induction of pro-carcinogenic genes by decitabine [5]. Although a specific role in normal and malignant hemopoiesis has not been demonstrated for Cyclophilin A, it is possible that its effects on inflammation, neutrophil chemo-attraction and induction of reactive oxygen species may be critical for leukemic cells $[28,29]$.Another interesting feature of our analysis is that decitabine is selectively able to down regulate alpha-Enolase. It could be that this occurs because of decitabine site-specific DNA incorporation. Certainly, by decreasing alpha-Enolase activity, decitabine could act reducing leukemic proliferation. Moreover, only treatment with decitabine down-regulates HSP60, which indeed plays a pivotal role in leukemogenesis [30].

Differences between the mechanisms of azacitidine and decitabine were observed in their activities on cell viability, protein synthesis, cell cycle, miRNA and gene expression $[3,5,6]$. The hypothesis that AZA and DAC have finely diverse biomolecular mechanisms is supported by the observation that these two agents have a specific and selective modulation of the target proteins which we identified. Their effects could be caused not exclusively by DNA hypomethylation. Our observations further indicate that azacitidine and decitabine are not interchangeable and that their alternate or combined use in clinics may be conceivable.

\section{Conflict of interest}

All authors have no conflict of interest to declare.

\section{Acknowledgments}

Contributions. V.S. designed the study and wrote the manuscript; F.B. performed experiments and wrote the results section; G.F. 
performed mass spectrometry analysis; E.S. and E.M. performed Western blot experiments and A.S., A.G. and A.B. took part in designing the study and revised the manuscript. Fundings. Regione Toscana, Bando Salute 2009; Ente Cassa di Risparmio di Firenze (ECR); and Ministero per l'Istruzione, l'Università e la Ricerca (MIUR).

\section{Appendix A. Supplementary data}

Supplementary data associated with this article can be found, in the online version, at doi:10.1016/j.leukres.2011.11.024.

\section{References}

[1] Santini V, Kantarjian HM, Issa JP. Changes in DNA methylation in neoplasia: pathophysiology and therapeutic implications. Ann Intern Med 2001;134:573-86.

[2] Santini V. Azacitidine: activity and efficacy as an epigenetic treatment of myelodysplastic syndromes. Expert Rev Hematol 2009;2:121-7.

[3] Hollenbach PW, Nguyen AN, Brady H, Williams M, Ning Y, Richard N, et al. A comparison of azacitidine and decitabine activities in acute myeloid leukemia cell lines. PLoS One 2010;5:e9001.

[4] Li LH, Olin EJ, Buskirk HH, Reineke LM. Cytotoxicity and mode of action of 5-azacytidine on L1210 leukemia. Cancer Res 1970;30:2760-9.

[5] Qiu X, Hother C, Ralfkiaer UM, Sogaard A, Lu Q, Workman CT, et al. Equitoxic doses of 5-azacytidine and 5-aza-2'deoxycytidine induce diverse immediate and overlapping heritable changes in the transcriptome. PLoS One 2010;5:e12994.

[6] Flotho C, Claus R, Batz C, Schneider M, Sandrock I, Ihde S, et al. The DNA methyltransferase inhibitors azacitidine, decitabine and zebularine exert differential effects on cancer gene expression in acute myeloid leukemia cells. Leukemia 2009;23:1019-28.

[7] Gozzini A, Rovida E, Dello Sbarba P, Galimberti S, Santini V. Butyrates, as a single drug, induce histone acetylation and granulocytic maturation: possible selectivity on core binding factor-acute myeloid leukemia blasts. Cancer Res 2003;63:8955-61.

[8] Barbetti V, Gozzini A, Rovida E, Morandi A, Spinelli E, Fossati G, et al. Selective anti-leukaemic activity of low-dose histone deacetylase inhibitor ITF2357 on AML1/ETO-positive cells. Oncogene 2008;27:1767-78.

[9] Santini V. A selective activity of DNMTi decitabine on AML1ETO positive cells? Leuk Res 2007;31:741-2.

[10] Gozzini A, Santini V. Butyrates and decitabine cooperate to induce histone acetylation and granulocytic maturation of $t(8 ; 21)$ acute myeloid leukemia blasts. Ann Hematol 2005;84(Suppl 1):54-60.

[11] Berg T, Guo Y, Abdelkarim M, Fliegauf M, Lubbert M. Reversal of p15/INK4b hypermethylation in AML1/ETO-positive and -negative myeloid leukemia cell lines. Leuk Res 2007;31:497-506.

[12] Stresemann C, Brueckner B, Musch T, Stopper H, Lyko F. Functional diversity of DNA methyltransferase inhibitors in human cancer cell lines. Cancer Res 2006;66:2794-800.

[13] Ferrari G, Pastorelli R, Buchi F, Spinelli E, Gozzini A, Bosi A, et al. Comparative proteomic analysis of chronic myelogenous leukemia cells: inside the mechanism of imatinib resistance. J Proteome Res 2007;6:367-75.
[14] Fenaux P, Mufti GJ, Hellstrom-Lindberg E, Santini V, Finelli C, Giagounidis A, et al. Efficacy of azacitidine compared with that of conventional care regimens in the treatment of higher-risk myelodysplastic syndromes: a randomised, open-label, phase III study. Lancet Oncol 2009;10:223-32.

[15] Wijermans PW, Ruter B, Baer MR, Slack JL, Saba HI, Lubbert M. Efficacy of decitabine in the treatment of patients with chronic myelomonocytic leukemia (CMML). Leuk Res 2008;32:587-91.

[16] Fandy TE, Herman JG, Kerns P, Jiemjit A, Sugar EA, Choi SH, et al. Early epigenetic changes and DNA damage do not predict clinical response in an overlapping schedule of 5-azacytidine and entinostat in patients with myeloid malignancies. Blood 2009;114:2764-73.

[17] Bianchi L, Bruzzese F, Leone A, Gagliardi A, Puglia M, Di Gennaro F, et al. Proteomic analysis identifies differentially expressed proteins after HDAC vorinostat and EGFR inhibitor gefitinib treatments in Hep-2 cancer cells. Proteomics 2011;11:3725-42.

[18] Buchi F, Pastorelli R, Ferrari G, Spinelli E, Gozzini A, Sassolini F, et al. Acetylome and phosphoproteome modifications in imatinib resistant chronic myeloid leukaemia cells treated with valproic acid. Leuk Res 2011;35: 921-31.

[19] Coghlin C, Carpenter B, Dundas SR, Lawrie LC, Telfer C, Murray GI. Characterization and over-expression of chaperonin $t$-complex proteins in colorectal cancer. J Pathol 2006;210:351-7.

[20] Gold LI, Eggleton P, Sweetwyne MT, Van Duyn LB, Greives MR, Naylor SM, et al. Calreticulin: non-endoplasmic reticulum functions in physiology and disease. FASEB J 2010;24:665-83.

[21] Lee HS, Lee JH, Hur EH, Lee MJ, Lee JH, Kim DY, et al. Clinical significance of GSTM1 and GSTT1 polymorphisms in younger patients with acute myeloid leukemia of intermediate-risk cytogenetics. Leuk Res 2009;33:426-33.

[22] Voso MT, Hohaus S, Guidi F, Fabiani E, D’Alo F, Groner S, et al. Prognostic role of glutathione S-transferase polymorphisms in acute myeloid leukemia. Leukemia 2008;22:1685-91.

[23] Chen ZY, Cai L, Zhu J, Chen M, Chen J, Li ZH, et al. Fyn requires HnRNPA2B1 and Sam68 to synergistically regulate apoptosis in pancreatic cancer. Carcinogenesis 2011;32:1419-26.

[24] Ohshima K, Karube K, Shimazaki K, Kamma H, Suzumiya J, Hamasaki M, et al. Imbalance between apoptosis and telomerase activity in myelodysplastic syndromes: possible role in ineffective hemopoiesis. Leuk Lymphoma 2003;44:1339-46.

[25] Ma YL, Peng JY, Zhang P, Huang L, Liu WJ, Shen TY, et al. Heterogeneous nuclear ribonucleoprotein A1 is identified as a potential biomarker for colorectal cancer based on differential proteomics technology. J Proteome Res 2009;8: 4525-35.

[26] Shi Y, Frost PJ, Hoang BQ, Benavides A, Sharma S, Gera JF, et al. IL-6-induced stimulation of c-myc translation in multiple myeloma cells is mediated by myc internal ribosome entry site function and the RNA-binding protein, hnRNP A1. Cancer Res 2008;68:10215-22.

[27] Hachiya M, Akashi M. Catalase regulates cell growth in HL60 human promyelocytic cells: evidence for growth regulation by $\mathrm{H}(2) \mathrm{O}(2)$. Radiat Res 2005;163:271-82.

[28] Satoh K, Berk BC, Shimokawa H. Vascular-derived reactive oxygen species for homeostasis and diseases. Nitric Oxide 2011;25:211-5.

[29] Song F, Zhang X, Ren XB, Zhu P, Xu J, Wang L, et al. Cyclophilin A (CyPA) induces chemotaxis independent of its peptidylprolyl cis-trans isomerase activity: direct binding between CyPA and the ectodomain of CD147. J Biol Chem 2011;286:8197-203.

[30] Sedlackova L, Spacek M, Holler E, Imryskova Z, Hromadnikova I. Heat-shock protein expression in leukemia. Tumour Biol 2011;32:33-44. 